\title{
The Quality in Higher Education through Teamwork
}

\author{
Mr. Ramesh Chand ${ }^{1}$, Mr. Ghansham Goyal ${ }^{2}$, Dr. Binay Kumar ${ }^{3}$, Dr. Kumar $^{4}$ \\ ${ }^{I}$ Graduated in Mechanical Engineering under North Maharastra University, Maharastra. \\ ${ }^{2}$ Graduated in Mechanical Engineering under Punjabi University, Patiala, Punjab. \\ ${ }^{3}$ Graduated in Mechanical Engineering under 'The Institution of Engineers (India). \\ ${ }^{4}$ Served many Institutions as Director, Principal, HOD, Professor and other posts.
}

\begin{abstract}
The quality in higher education is mainly about the economic development, which depends on quality approaches in higher education. The quality education in higher system facilitates, the physical, mental, social, emotional and spiritual development. The quality education has become watchword and indeed the corner stone for any higher technical educational system. The authors have in mind the quality circles or teamwork approaches can have for maintaining and improving the quality in higher technical education as per available resources to raise the institute at the competitive highest level to solve unemployment. The concept assumes that people closest to the problem understand better than who maintain the system from outsides. It hopes that a group of individuals working together will come up with better solution than one individual working alone. Quality circles approaches are a specifically structured form and mode of for betterment of management system.
\end{abstract}

Key Word: Teamwork, Quality in Higher Education, Discipline, Positive Approaches, Motivation.

\section{Introduction}

Quality Circles are defined by Maurice Alston: "Quality Circles are small group of people doing similar work who, together with their supervisors volunteer to meet for an hour a week to study and solve work related problems which affect them." Circle leaders and members are trained in simple problem solving techniques, which identify causes and develop solutions. Presentations are made by the quality circles at an appropriate time to the management who decide whether to accept, modify or decline the proposals. A quality control research group was formed as a part of the Japanese Union of Scientists and Engineers (JUSE). Quality circles evolved out of these research effects from the combination of two aspects namely statistical techniques and group orientation directed towards problem solving.

It has three major attributes as:

\section{Aspect Of Quality Circle}

1. Quality circle is a problem solving technique.

2. Quality circle is a human resource development technique.

3. Quality circle is a form of participative management.

The imperatives of quality and productivity, which lie at the heart of this new industrial competition, are impossible to satisfy without the active, loyal and committed, participation of a well trained and constantly improving work force. Every institution has a vast store of untapped talent, brains, learning abilities and ideas. The first step towards a institutional business philosophy conductive to quality circles is the discovery of this valuable resource by the measurement.

The key factors of quality circles are:

a. People will take pride and interest in their work if they experience autonomy and control over the decisions that affect them.

b. It helps to develop in employees sense of belongings towards a particular institution.

c. The concept of quality circles relies entirely upon intrinsic motivation i.e. from increased satisfaction, involvement in decision-making and the opportunity to satisfy higher order needs.

d. A belief that each employee desires to participate in making the institution a better place in which he works.

e. Recognition of the importance of development of human resources.

f. It implies the development of their skills, capabilities, confidence and creativity through the process of education, training, work experience and participation.

g. A willingness to allow people to volunteer their time and effort for any performance of the organization.

$\mathrm{h}$. The importance of each and every member's role and function in meeting institutional goals.

i. Quality circles were thought of, and created as an effective means of enabling every one involved in the institution to share his responsibility, knowledge, experience in a team effort for quality, student productivity and perfection. 


\section{Theory On Human Nature}

Scientist McGregor's has developed two theories:

Theory X: The average person is lazy, not interested in work, lacks initiative and avoids responsibility. Men therefore, need to be controlled and compelled to do the work.

Theory Y: Given conductive conditions, people desire to work and share responsibility. They derive satisfaction from good work. A positive sense of self-respect is important to them. Motivation, creativity and innovative ability are widely distributed among people.

Quality circles are in conformity with the theory ' $\mathrm{Y}$ ' of McGregor.

Maslow's hierarchy (Table 1. ) of six basic types of human needs explain the growing theory of worker motivation, which forms a philosophical basis of Quality Circles. These needs are arranged in sequential order in lower order needs have priority over higher order needs. Lower one need is satisfied the individual immediately moves to the next level. Human needs are required to be satisfied. People have reasons for doing what they do. They believe that they can satisfy their needs by taking particular course of action. The need, action and satisfaction are closely inter-related and all these factors relate intimately to motivation as given in Table 1.

TABLE 1: Human Needs and Way of Satisfaction

\begin{tabular}{|l|l|}
\hline Types of need & Ways in which the need can meet through' Quality Circles \\
\hline A. Physiological Needs & Quality Circles force to work to satisfy their needs \\
\hline B. Stimulation & Quality Circles provide important way to stimulate through and reduce boredom in workplace. \\
\hline C. Security & $\begin{array}{l}\text { Through Quality Circles employees can demonstrate their values to the organization and improve } \\
\text { productivity. }\end{array}$ \\
\hline D. Social Belonging & $\begin{array}{l}\text { Quality Circle provides an accepted social structure. } \\
\text { Team building and acceptance are part of Quality Circles training. }\end{array}$ \\
\hline E. Esteem & $\begin{array}{l}\text { Successful Quality Circle projects receive recognition and generate for the talent and expertise of the } \\
\text { individual member as well as the team. }\end{array}$ \\
\hline F. Self Actualization & $\begin{array}{l}\text { Quality Circles combine opportunities to use knowledge, judgment and creativity with freedom to } \\
\text { decide how to contribute. }\end{array}$ \\
\hline
\end{tabular}

\section{Objectives Of Institution}

a. To improve the quality and student productivity.

b. To reduce the cost of good quality of student product.

c. To identity and solve work related problems that interface with quality production.

d. To tap the creative intelligence of the persons working in the institution and to make full use of its human resources.

e. To permit employees to develop and use greater amount of knowledge and skill and motivate them to apply to a wide range of challenging tasks.

f. To improve communication within the institution.

g. To increase employees loyalty and commitment to the institution and its goals.

h. To respect humanity and build a happy bright work place environment which is meaningful to work in.

i. To enrich human capability, confidence, moral, attitude and relationship.

j. To satisfy the human needs of recognition, achievement and self-development.

\section{Benefits of System}

a. Promote high level of students and quality mindedness.

b. Self and mutual development of students, faculties and assisting staff.

c. Creating team spirit and unity of action in the institution.

d. Increase motivation, job satisfaction and pride in their work.

e. Reduces absenteeism and develop friendly atmosphere.

f. Developing sense of willingness towards a particular institution.

g. Reducing cast and religion feelings.

h. Improve communications.

i. Safety improvement.

j. Increased utilization human resource potential.

k. Enhancement in consciousness and moral of faculties \& staffs through recognition of their activities.

1. Leadership development.

m. Trained staff.

n. Identifies work related problems and solves them efficiently and effectively. 


\section{Limitations On System Approach:}

a. The overall performance may decrease initially at the beginning of quality circles, as the members turn from their work to the task of organizing themselves and undergoing training.

b. A large investment of time and money is required for a concept that is essentially new and unproven in the institutional context.

c. The chance of errors increases initially. Mistakes are inevitable as employees adjust to a new way of doing things.

d. Over-expectation of some faculties or staffs who are very much exited initially may turn to disappointment and drop out.

e. Teamwork may threaten traditional authority structure. Threatened authorities are likely to resist and noncooperate with the circle activities.

f. Staffs who are habituated to depend on their supervisors for direction and who have lost their initiative feel uncomfortable with quality circles.

g. After circle implementation, a period of confusion may arise. This is because of member experiment with new ideas, new skills and new roles.

h. Changes in system and control may become necessary.

\section{Coordination With Institute-Industry}

The Table 2 analysis would be helpful in appreciating the managerial function for betterment.

\section{Table 2: MANAGERIAL ROLES IN BETTERMENT}

Members: Teachers/Office Superintendent

$>$ Keep focus on problem related work.

$>$ Not interfere for personal problem.

$>$ Demonstrate mutual respect.

$>$ Offer views freely in problem solving.

$>$ Attempt all meetings.

$>$ Contribute to finding solutions of problems.

$>$ Contribute to implementing solutions.

$>$ Attend training seriously with respective attitude.

$>$ Acquire skills to contribute to the problem solving activities.

\section{Leader: Head Of Department/Registrar}

$>$ Conduct meetings and ensure participation by all faculties.

$>$ Help in collecting data.

$>$ Transmit quality circle suggestions to facilitator.

$>$ Interact among themselves and facilitator.

$>$ Present solutions and suggestions to management.

$>$ Maintain relevant records of meetings.

$>$ Ensure implementation of solutions by the group.

$>$ Keeping the circles informed about status of previously submitted suggestions.

$>$ Keeping meeting positive and on track.

$>$ Training circle members in group process and in the use of tools and techniques for generating ideas and problem solutions.

\section{Facilitator: Principal}

$>$ Coordinate the work of several quality circles through leader.

$>$ Serve as a resource to the Group/ Circle.

$>$ Arrange for expertise from other groups/ institutions/ organizations.

$>$ Keep the circle on track.

$>$ Acquire skill through training program.

$>$ Transfer skills to members of quality circles.

$>$ Transmit proposals /solutions to management.

$>$ Arrange for training for quality circles members.

$>$ Provide feedback to members/ management.

$>$ Maintain budgets and keep cost records.

$>$ Help circles to provide presentation to management. 
The success of quality circle depends mainly upon the proper selection of suitable personnel as facilitator, which serves as a coach for the circle leaders and a process consultant to the circles. Facilitator is a vital man to the management.

\section{Management: Director/ Chairman}

$>$ Officially announces the initiation of the quality circle movement and stress the necessity to establish quality circles and highlight its features and utility.

$>$ Assist/contribute to the development of the quality circle models and structure.

$>$ Provide opportunities to quality circles to present their solutions and to implement accepted solution after evaluation.

$>$ Provide resources like space, time, training facilities, finance, etc.

$>$ Ensure adequate training opportunities to facilitator quality circle leaders and members.

$>$ Consider suggestions of quality circles fairly and justly.

$>$ Recognize the contributions of the facilitator.

$>$ Encourage the movement.

$>$ Communicate the decisions to quality circles.

$>$ Arrange for external specialist help.

$>$ Develop guidelines for measurement of circles activities.

$>$ Periodically review the progress.

\section{Conclusions And Scope}

The scope of quality controls is not limited by a narrow definition of quality. It is concerned with the concept of total customer satisfaction with products and services and not merely with conformance with some standards or specifications in the institution or organization. It is often said that personality is the sum of person's capabilities and development abilities and for a teacher it is important both outside as well as in the classroom. Students come from varied backgrounds and all of them bring with them strengths and weaknesses, their likes and dislikes, etc. The teaching is not a pouring-in process but it needs explanations, illustration and examples at the same wavelength as those of the students. A teacher has to impart knowledge very successfully while responding to the abilities, emotions, attitude and behaviour of the students by way of intense interaction through quality circles or teamwork.

Quality Circles/ Teamwork certainly raise the institute at the highest level with the guidelines of responsibilities are carried out by the institutional system. It has a wide scope for group-based solution of work related problems. Quality circles are relevant for every place where peoples are involved in the solution of problems and improvement of work like factories, fires, schools, hospitals, universities, banks, government offices, etc.

\section{References}

[1]. Sen A. K, "Industrialization and Training”, Indian Journal of Technical Education, 21(4),P 24-27,1988

[2]. Willborb W. W, "Quality Audits and Technological Excellence", International Journal of Quality and Reliability Management, Vol.-6, 1989.

[3]. Indurwade N. H, "Impact of Industry-Institute interaction of Upgradation of R\&D facilities in the Pharmaceutical Field" The Indian Journal of Technical Education, Vol-20, No.2, Apr-June, 1997.

[4]. Modek J. P., "Research and Development activities at a Self Financing Institution at Degree Level", Indian Journal of Technical Education, 23(2), P 35-38, 2000

[5]. Thomas S., Kumar B. , “ The Quality of Mining System Through Betterment of Technical Education - A Long-Range Objective”, $11^{\text {th }}$ International Conference on Productivity and Quality Research at Indian Institute of Technology, Delhi, Dec 12-15, 2005.PP.

[6]. Nahai R., Osterberg S., Ennals R., “A Perspective from A Students' Quality Circle”, Nova Science Publishers, Inc., pp. ISBN 978$1-61209-686-5,2011$.

[7]. Kumar B. , Gupta V. ," The Challenging Role of Technical Institution for The Betterment of Mining System \& Safety in Mineral Industry for Economic Growth of the Country", International Journal of Research \& Development in Technology and Management Sciences-Kailash, June 2014, ISBN-1-63102-447-7, European Article Number [EAN]-978-163-102-447-4, Volume 21, Issue - 3 page $61-72$

[8]. Kumar B. , Paul S. R. ,'The Quality Consciousness in Engineering Education - An Alarming Attention", International Journal of Science \& Technology, ISSN (online): 2250-141X, Vol. 6 Issue 3, July 2016, P24-34. 